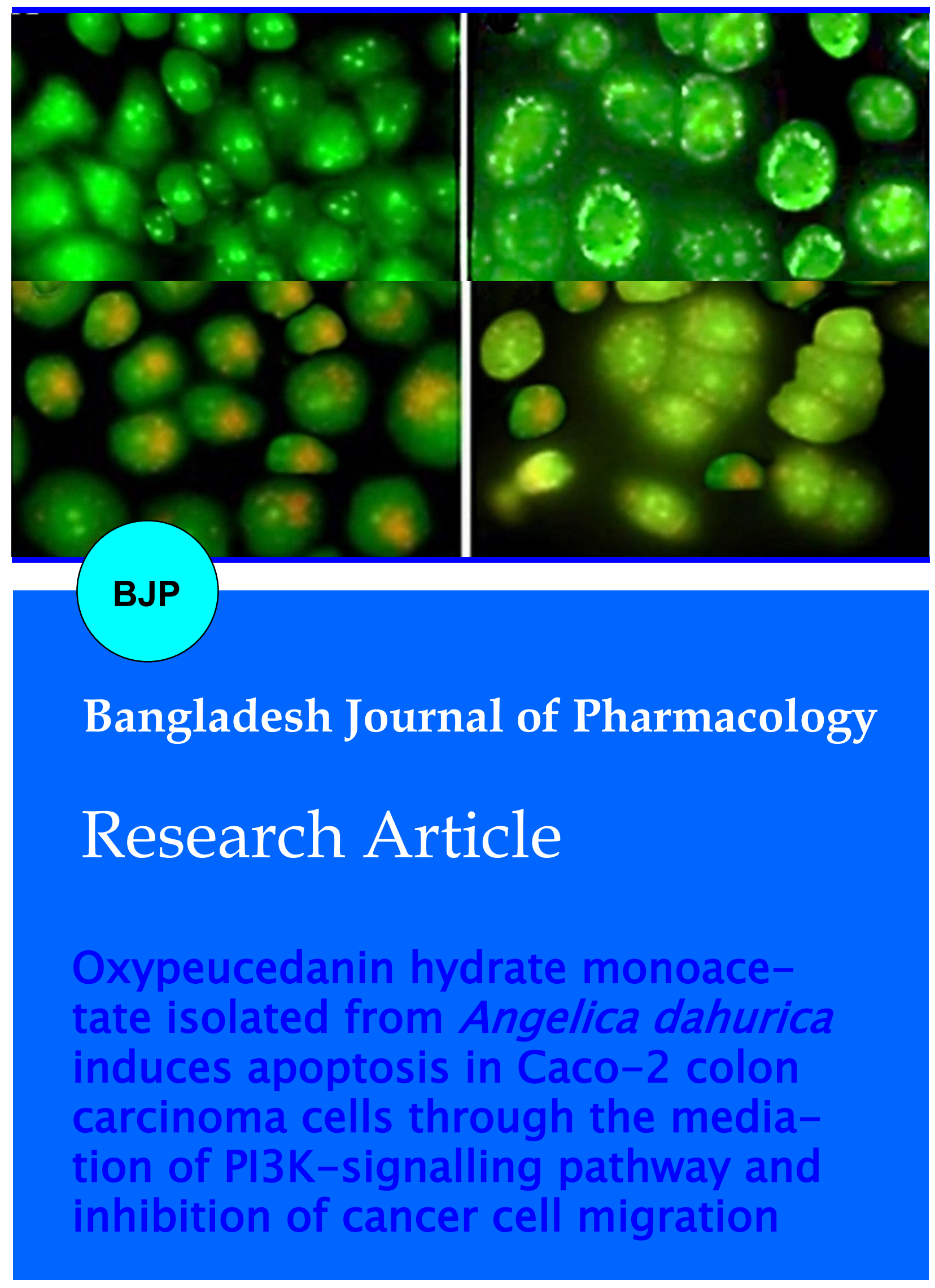


Abstracted/indexed in Academic Search Complete, Asia Journals Online, Bangladesh Journals Online, Biological Abstracts, BIOSIS Previews, CAB Abstracts, Current Abstracts, Directory of Open Access Journals, EMBASE/Excerpta Medica, Google Scholar, HINARI (WHO), International Pharmaceutical Abstracts, Open J-gate, Science Citation Index Expanded, SCOPUS and Social Sciences Citation Index;

ISSN: $1991-0088$

\title{
Oxypeucedanin hydrate monoacetate isolated from Angelica dahurica induces apoptosis in Caco-2 colon carcinoma cells through the mediation of PI3K-signalling pathway and inhibition of cancer cell migration
}

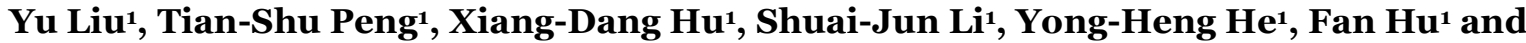 \\ Jinbo Jiang ${ }^{2}$ \\ ${ }^{1}$ Department of Anorectal Disease, The Second Affiliated Hospital of Hunan University of Chinese Medicine, \\ Changsha, Hunan 410 005, China; ' 2 Department of Blood and Oncology, The First Affiliated Hospital of Hunan \\ University of Chinese Medicine, Changsha, Hunan 410 007, China.
}

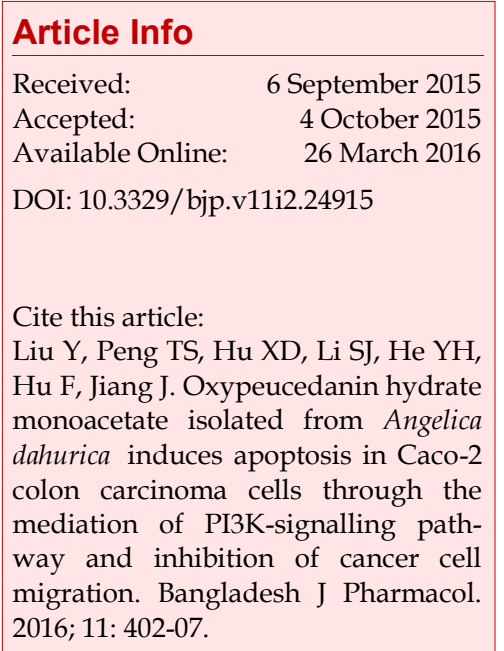

\begin{abstract}
The main aim of the present research work was to demonstrate the antitumor and apoptotic activities of oxypeucedanin hydrate monoacetate isolated from Angelica dahurica against Caco-2 colon cancer cells. MTT cell viability assay along with clonogenic assays were used to study the effect of the compound on cell cytotoxicity and the colony forming tendency. Fluorescence microscopy using acridine orange/ethidium bromide was used to study the effects on apoptosis. In vitro wound healing assay and Western blotting were carried out to study effect on cell migration and PI3K-signalling pathway. The results revealed that oxypeucedanin hydrate monoacetate inhibited Caco-2 cell proliferation and decreased the number of cancer colony forming cells. This compound exerted anti-migratory effects in dose- and time-dependent manner. As compared to the untreated control, drug-treated cells showed significant inhibition of cancer cell migration. Oxypeucedanin hydrate monoacetate significantly down-regulated the expression of pAkt and pPI3K in Caco-2 cells.
\end{abstract}

\section{Introduction}

Malignant cancer disorders constitute one of the leading causes of death in most countries. The process of carcinogenesis is a complex biochemical process involving several signalling pathways. So, understanding of these underlying cellular pathways constitutes one of the effective and novel strategies to target uncontrolled cell division in tumor tissues.

Focus has been put on finding novel chemotherapeutic agents which can interfere with these cellular processes and thus inhibit tumor growth and eventually can be used as an anti-cancer drug (Jemal et al., 2011). Colon cancer is ranked as $3^{\text {rd }}$ leading causes of cancer-related mortality in the western world. In the developing countries, the prevalence of colon cancer is on the rise due to many key factors including changing food habits coupled with increasing life expectancy. As such, colon cancer is a serious public threat throughout the globe and needs urgent attention (Lin et al., 2007). There are various factors which give rise to colon cancer and these include mutations in adenomatous polyposis coli, loss in tumor suppressor gene p53, disruption in cell cycle and suppression in apoptosis (Kinzler and Vogelstein, 1996; Samowitz et al., 2002; Sebolt-Leopold et al., 1999; Torrance et al., 2000). It follows therefore, agents which can manage these above mentioned defects could as potential chemotherapeutic agents in controlling the growth of colon cancer cells.

The objective of the current research work was to study 
the antitumor effect of oxypeucedanin hydrate monoacetate isolated from the ethyl acetate extract of Angelica dahurica against Caco- 2 colon cancer cells by studying its effect on apoptosis, cancer cell migration and PI3Ksignalling pathway.

\section{Materials and Methods}

\section{Plant material}

The roots of the plant were collected from Zhengzhou City, China and identified by Prof. Ying Yang. A voucher specimen (Voucher specimen number: 19-087011-15) was deposited in the Herbarium of Southeast University, Nanjing, China.

\section{Extraction and isolation of oxypeucedanin hydrate} monoacetate

The air dried, finely powdered roots of the fruit $(10 \mathrm{~kg})$ was extracted for 48 hours with ethyl acetate in a soxhlet apparatus to yield the extract, which was concentrated under reduced pressure. The ethyl acetate extract (80 g) was loaded on silica gel (60-120 mesh, 500 g) column and eluted with an increasing gradient of petroleum ether and chloroform. Fractions of $100 \mathrm{~mL}$ volume each were collected and pooled according to TLC pattern.

Three major fractions were collected (80:20, 60:40, 40:60). The fraction (petroleum ether: chloroform, 60:40) yielded oxypeucedanin hydrate monoacetate as colorless crystalline solid, showing molecular ion peak in the mass spectrum at $\mathrm{m} / \mathrm{z}$ : 346 analyzed for $\mathrm{C}_{18} \mathrm{H}_{18} \mathrm{O}_{7}$. The IR spectrum showed prominent peak at $3400 \mathrm{~cm}^{-1}(-$ $\mathrm{OH}), 1738$ and $1244 \mathrm{~cm}^{-1}\left(-\mathrm{OCOCH}_{3}\right), 1716(\alpha, \beta-$ unsaturated $\delta$-lactone), 1603 and $1497 \mathrm{~cm}^{-1}$ (aromatic), 1382 and $1367 \mathrm{~cm}^{-1}$ (gemdimethyl). In its ${ }^{1} \mathrm{H}$ NMR spectrum, displayed a resonance signal at $\delta 2.06(3 \mathrm{H}, \mathrm{s}$, C-2" acetate protons) and down field resonance signals due to olefinic protons at $\delta 6.20(1 \mathrm{H}, \mathrm{d}, \mathrm{J}=9.0 \mathrm{~Hz}, \mathrm{H}-3)$, $8.14(1 \mathrm{H}, \mathrm{d}, \mathrm{J}=9.0 \mathrm{~Hz}, \mathrm{H}-4), 7.60\left(1 \mathrm{H}, \mathrm{d}, \mathrm{J}=2.2 \mathrm{~Hz}, \mathrm{H}-2^{\prime}\right.$ furano $\alpha-\mathrm{H}), 6.91\left(1 \mathrm{H}, \mathrm{d}, \mathrm{J}=2.2, \mathrm{H}-3^{\prime}\right.$ furano $\left.\beta-\mathrm{H}\right)$, besides a signal at $\delta 7.07(1 \mathrm{H}, \mathrm{s})$ due to an aromatic proton $(\mathrm{H}-$ 8).

Further, the ${ }^{1} \mathrm{H}$ NMR spectra of the compound displayed the resonance signals at $\delta 4.59$ (2H, m, H-1"), $5.34\left(1 \mathrm{H}, \mathrm{m}, \mathrm{H}-2^{\prime \prime}\right)$, besides broad signals at $\delta 3.71(1 \mathrm{H}$, bs, 3 " $-\mathrm{OH}$, exchangeable with $\mathrm{D} 2 \mathrm{O})$. The signal at $\delta 1.33$ $(6 \mathrm{H}, \mathrm{s})$ was assigned to gemdimethyl protons. The chemical shift of gemdimethyl indicates that these are attached to carbon, bearing oxygen function. Also, the downfield resonance signal at $\delta 4.59$ displayed by two protons at $\mathrm{C}-\mathrm{1}^{\prime \prime}$ indicates that $\mathrm{C}-\mathrm{1}^{\prime \prime}$ is attached to the aromatic ring through oxygen atom.

In the ${ }^{13} \mathrm{C}$ NMR spectrum, 18 carbon signals were observed. Eleven carbons were assigned for a furanocoumarin nucleus at $\delta \mathrm{C} 160.4(-\mathrm{OC}=\mathrm{O}, \mathrm{C}-2), 112.5$
(=CH, C-3), 140.1 (=CH, C-4), 106.2 (=C, C-4a), 149.2 (=C-O-, C-5), 113.6 (=C, C-6), 157.8 (=C, C-7), 94.3 (=C-, C-8), 145.7 (=C-O-, C-8a), $144.6\left(=\mathrm{CH}, \mathrm{C}-2^{\prime}\right)$, and 105.3 $\left(=\mathrm{CH}, \mathrm{C}-3^{\prime}\right)$.

\section{Cell line, culture conditions and MTT cell viability assay}

Caco-2 human colon cancer cells were obtained from Shanghai Institute of Cell Resource Center of Life Science (China). Cells were grown in Dulbecco's modified Eagle's medium (DMEM) supplemented with $10 \%$ fetal bovine serum and $100 \mathrm{U} / \mathrm{mL}$ penicillin and $100 \mu \mathrm{g} / \mathrm{mL}$ streptomycin. Cells were cultured in $\mathrm{CO}_{2}$ incubator with an internal atmosphere of $95 \%$ air and $5 \% \mathrm{CO}_{2}$ gas and the cell lines were maintained at $37^{\circ} \mathrm{C}$. In order to evaluate the effect of oxypeucedanin hydrate monoacetate on the cell proliferation, MTT assay was performed. Cells were seeded in 96-well plates $\left(1 \times 10^{6}\right.$ cells/well). The cells were treated with the various doses of the compound $(0,4,12,24,48,96$ and $150 \mu \mathrm{M}$ ) for 24,48 and 72 hours time intervals. Subsequently, MTT solution (5 mg/mL) was then added to each well. After 4 hours incubation time, formazan precipitate was dissolved in $500 \mu \mathrm{L}$ dimethyl sulfoxide, and then the absorbance was measured in automated microplated reader (Bio-Tek, USA) at 570 $\mathrm{nm}$. The cell viability ratio was calculated by the following formula:

Inhibitory ratio $(\%)=(\mathrm{OD}$ control $-\mathrm{OD}$ treated $) / \mathrm{OD}$ control $\times 100 \%$

Cytotoxicity was expressed as the concentration of oxypeucedanin hydrate monoacetate inhibiting cell growth by $50 \%$ ( $\mathrm{IC}_{50}$ value).

\section{Colony formation assay}

Cells were suspended in $1 \mathrm{~mL}$ of Dulbecco's modified Eagle's medium containing 0.5\% agarose (Amresco, USA) and $10 \%$ FBS, and plated on a bottom layer containing $0.8 \%$ agarose and $10 \%$ fetal bovine serum in 6-well plate in triplicate. After 4 days, plates were stained with $0.3 \%$ gentian violet and the colonies were counted under light microscope.

\section{In vitro wound healing assay for studying cancer cell migration}

In vitro wound healing assay was performed as per are ported method (Liang et al., 2007). Caco-2 colon cancer cells $\left(1 \times 10^{6}\right.$ cells $\left./ \mathrm{mL}\right)$ were seeded in a 6 -well plate and incubated at $37^{\circ} \mathrm{C}$ until $100 \%$ full confluent monolayer was achieved. Following 10 hours of starvation, a $250 \mathrm{~mL}$ pipette tip was used to produce a straight cellfree wound. Each well was washed twice with PBS to remove any debris and then exposed to numerous concentrations of oxypeucedanin hydrate monoacetate $(0,24,48$ and $150 \mu \mathrm{M})$ in a medium. After 48 hours of incubation, the cells were fixed and stained with $3 \%$ ethanol comprising $0.5 \%$ crystal violet powder for 30 
min, and arbitrarily chosen fields were photographed under a light microscope (Olympus, USA). The number of cells that migrated into the scratched area were counted.

\section{Morphological study of apoptosis using fluorescence microscopy and AO/EB staining}

Cells were seeded at a concentration of $3 \times 10^{5}$ cell $/ \mathrm{mL}$ in a volume of $2 \mathrm{~mL}$ on sterile cover slip in 6-well tissue culture plates. Subsequent to incubation, the medium was removed and replaced with fresh medium plus $5 \%$ FBS and supplemented with oxypeucedanin hydrate monoacetate $(0,24,48$ and $150 \mu \mathrm{M})$. Following the drug treatment, the cover slip with monolayer cells was inverted on the glass slide with $10 \mu \mathrm{L}$ of $\mathrm{AO} / \mathrm{EB}$ stain $(50 \mu \mathrm{g} / \mathrm{mL})$. The staining images were recorded using a UV fluorescence microscope (Olympus, Japan) using UV filter at 400x magnification to detect morphological evidence of apoptosis.

\section{Western blot assay}

Briefly, after cells were treated with oxypeucedanin hydrate monoacetate, the total proteins were extracted with RIPA lysis buffer containing 1\% cocktail and 1\% phenylmethane sulfonylfluoride (PMSF). Protein concentrations were measured by Bio-Rad protein assay kit (Bio-Rad, USA). Equivalent amounts of proteins were separated by $8-12 \%$ sodium dodecyl sulfate polyacrylamide gel electrophoresis and then electro transferred to a nitrocellulose membrane. After washing with TBST, the membrane was incubated with the corresponding secondary antibodies (1:10000). To probe for pPI3K, Akt, pAkt, Bcl-2, Bax, Bcl-xl, Bad, Cytochrome $\mathrm{C}$, cleaved caspase-3, cleaved-PARP, and $\beta$ -actin, membranes were incubated overnight at $4^{\circ} \mathrm{C}$ with the relevant antibodies. Signals were detected using an ECL Plus Chemiluminescence kit (Applygen Technologies Inc., China) on X-ray film.

\section{Statistical analysis}

All experiments were done in triplicate and the results are conveyed as the mean \pm standard deviation. Graphpad Prism (Graphpad Software, Inc., USA) was used for performing statistical analyses and $\mathrm{p}<0.05$ was taken to designate a statistically significant difference.

\section{Results}

\section{Anti-tumor activity against Caco-2 colon cancer cells}

MTT assay revealed that oxypeucedanin hydrate monoacetate showed a potent growth inhibitory effect on the proliferation of Caco-2 cancer cells with $\mathrm{IC}_{50}$ values $36.4,42.1$ and $46.3 \mu \mathrm{M}$ at 72,48 and 24 hours time intervals respectively. Clonogenic assay revealed that oxypeucedanin hydrate monoacetate also leads to a significant reduction in the number of cancer colony forming cells which showed strong dose-dependence (Figure 1 and 2).

\section{Inhibits colon cancer cell migration}

Figure 3 shows the effect of oxypeucedanin hydrate monoacetate on the cell migration in Caco-2 cells, indicating that this compound exerts anti-migratory effects in a dose dependent manner. The cells were observed every 12 hours under the same observation field for wound healing position. After 12, 24 and 48 hours time intervals and after 24, 48 and $150 \mu \mathrm{M}$ compound doses, the cell migratory abilities decreased considerably as compared to DMSO control. In oxypeucedanin hydrate monoacetate-treated cells, the wound area was larger than that of control (DMSO).

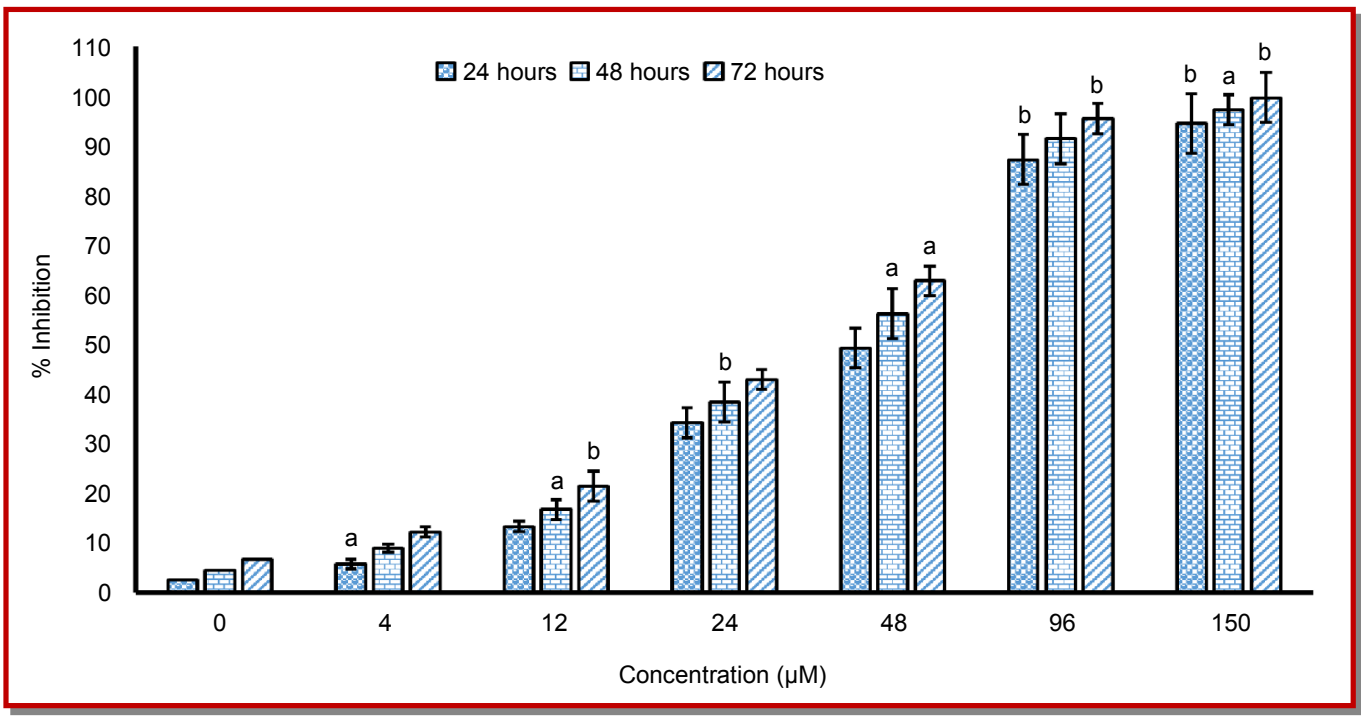

Figure 1: Dose- and time-dependent cytotoxic effect of oxypeucedanin hydrate monoacetate in human colon cancer cells (Caco2). Data are shown as the mean $\pm S D$ of three independent experiments. ${ }^{a} \mathrm{p}<0.05$, ${ }^{b} p<0.01$, vs $0 \mu \mathrm{M}$ (control) 


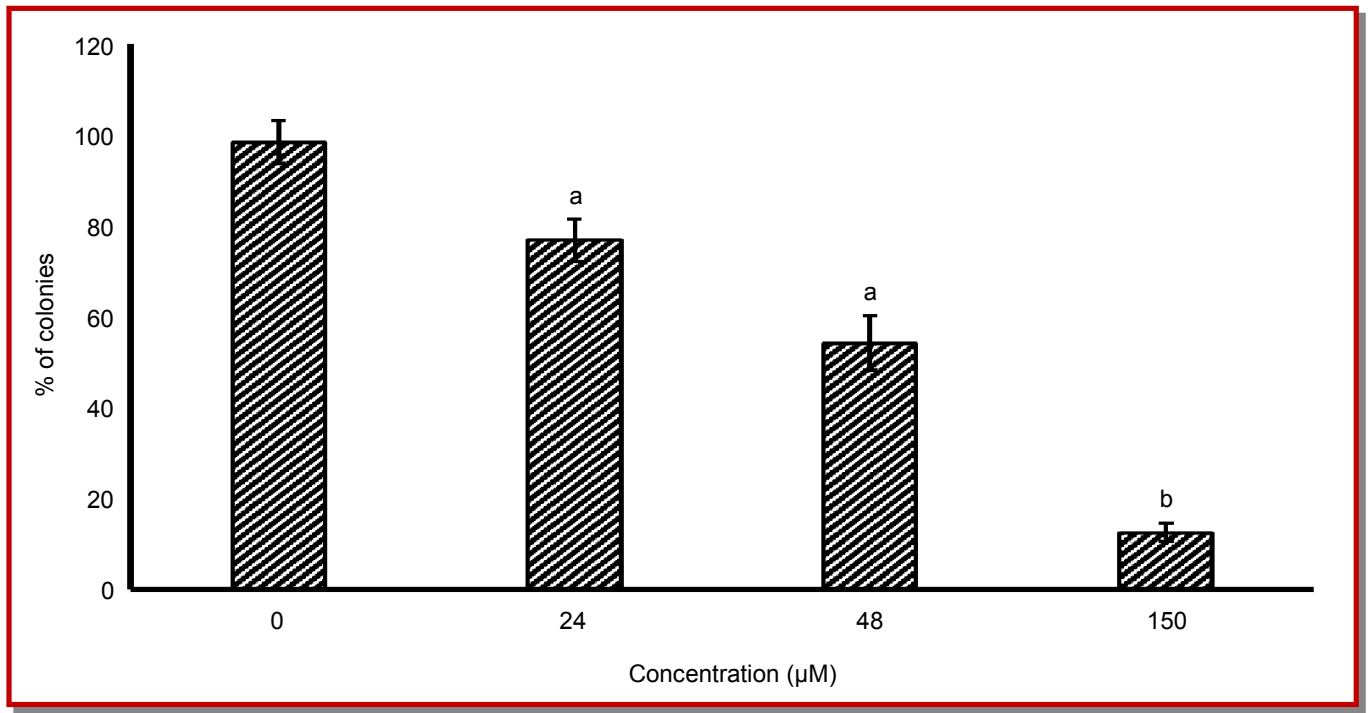

Figure 2: Inhibitory effect of oxypeucedanin hydrate monoacetate on human colon cancer cells (Caco-2). The colony formation assay of Caco- 2 cells treated with oxypeucedanin hydrate monoacetate at indicated doses

\section{Induces apoptosis in Caco-2}

The results revealed that oxypeucedanin hydrate monoacetate treatment at various doses showed apoptotic changes with yellow green spots in Caco-2 cell nuclei. Higher doses of the compound led to late apoptotic events characterized by orange staining with chromatin condensation and appearance of apoptotic bodies (Figure 4). These morphological changes are the characteristic features of apoptosis process.

\section{Induces apoptosis in Caco-2 cells via PI3K/Akt path- way}

It was observed that oxypeucedanin hydrate monoacetate significantly down-regulated the expression of
pAkt and pPI3K in Caco-2 cells in a dose-dependent manner although total Akt protein levels remained constant during all treatments (Figure 5).

\section{Discussion}

The results of the current study indicate that oxypeucedanin hydrate monoacetate induced growth inhibitory effects on the proliferation of Caco-2 human colon cancer cells in a dose- and time-dependent manner. Colony formation assay showed that the compound led to a reduction in the number of cancer colony forming cells. In vitro wound healing assay revealed that after 12, 24 and 48 hours time intervals and after 24, 48 and

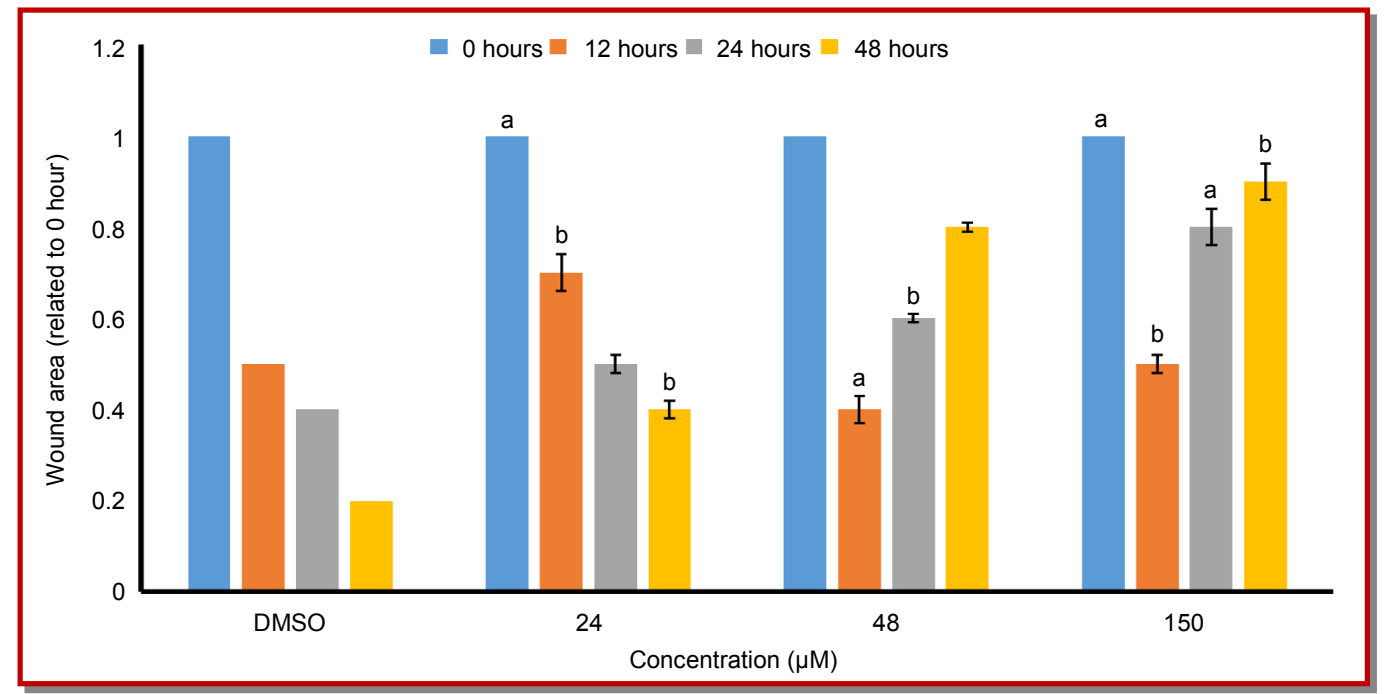

Figure 3: Oxypeucedanin hydrate monoacetate inhibits cell migration in the human colon cancer cells (Caco-2). A wound healing assay was done to determine the cell migration ability. Caco- 2 cells were treated with $0.2 \%$ DMSO or 24,48 and $150 \mu \mathrm{M}$ oxypeucedanin hydrate monoacetate for $0,12,24$ and 48 hours 


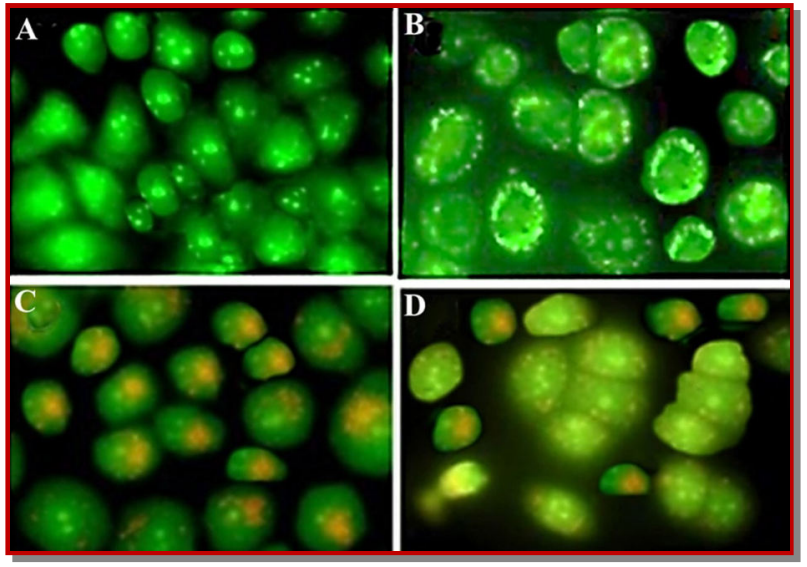

Figure 4: $\mathrm{AO} / \mathrm{EB}$ staining of caco-2 human colon cancer cells using fluorescence microscopy. After treating Caco-2 cells with different doses of oxypeucedanin hydrate monoacetate for 48 hours cells were stained and observed under fluorescence microscope. As compared to untreated control group (A), compound-treated cells (B-D) showed clear signs of early and late apoptosis. B, C and D represent effect of 24,48 and $150 \mu \mathrm{M}$ dose of oxypeucedanin hydrate monoacetate

$150 \mu \mathrm{M}$ compound doses, the cell migratory abilities decreased considerably as compared to DMSO control. In oxypeucedanin hydrate monoacetate-treated cells, the wound area was larger than that of control (DMSO). This indicated that the compound has the ability to suppress that migratory tendency of cancer cells and hence inhibit cell migration. Further, it was demonstrated that the growth inhibitory effects of oxypeucedanin hydrate monoacetate were mediated via the induction of apoptosis using fluorescence microscopy and $\mathrm{AO} / \mathrm{EB}$ staining in Caco-2 colon cancer cells. The results showed that lower doses of the compound induced early apoptotic effects characterized by yellowish staining while as higher doses of the compound induced late stage apoptosis marked by orange staining. Finally, the effect of the compound on a crucial signalling pathway known as the PI3K/Akt pathway were observed. This pathway has been known to have a key role in tumorigenesis process and apoptosis. It was observed that oxypeuce-danin hydrate monoacetate significantly down-regula-ted the expression of pAkt and pPI3K in Caco-2 cells in a dosedependent manner.

Inducing apoptosis in cancer cells is one of the main features of many anti-cancer drugs leading to cancer prevention via controlling cell death. Morphological features of apoptosis include chromatin condensation and nuclear margination (Hale et al., 1996; Kerr et al., 1972; Fadeel et al., 1999; Reed and Tomaselli, 2000). Migration and invasion of malignant cancers are two key features resulting in high morbidity. These are the features of cancer progression and metastasis. It has earlier been reported that cell migration is regulated by several signalling pathways including PI3K, p38MAPK, pJNK and FAK (Lee et al., 2008; Neudauer and McCarthy, 2003). Consequently, research efforts in this direction can result in the therapeutic methods for preventing cancer invasion, migration and metastasis ultimately resulting in improvement of the survival of the cancer patients. Apoptosis is a highly specialized biochemical process which eradicates redundant cells from the body and as such is the key for maintaining tissue homeostasis. Any disturbance in this process eventually results in numerous diseases including cancer. Both intrinsic as well as extrinsic stimuli can

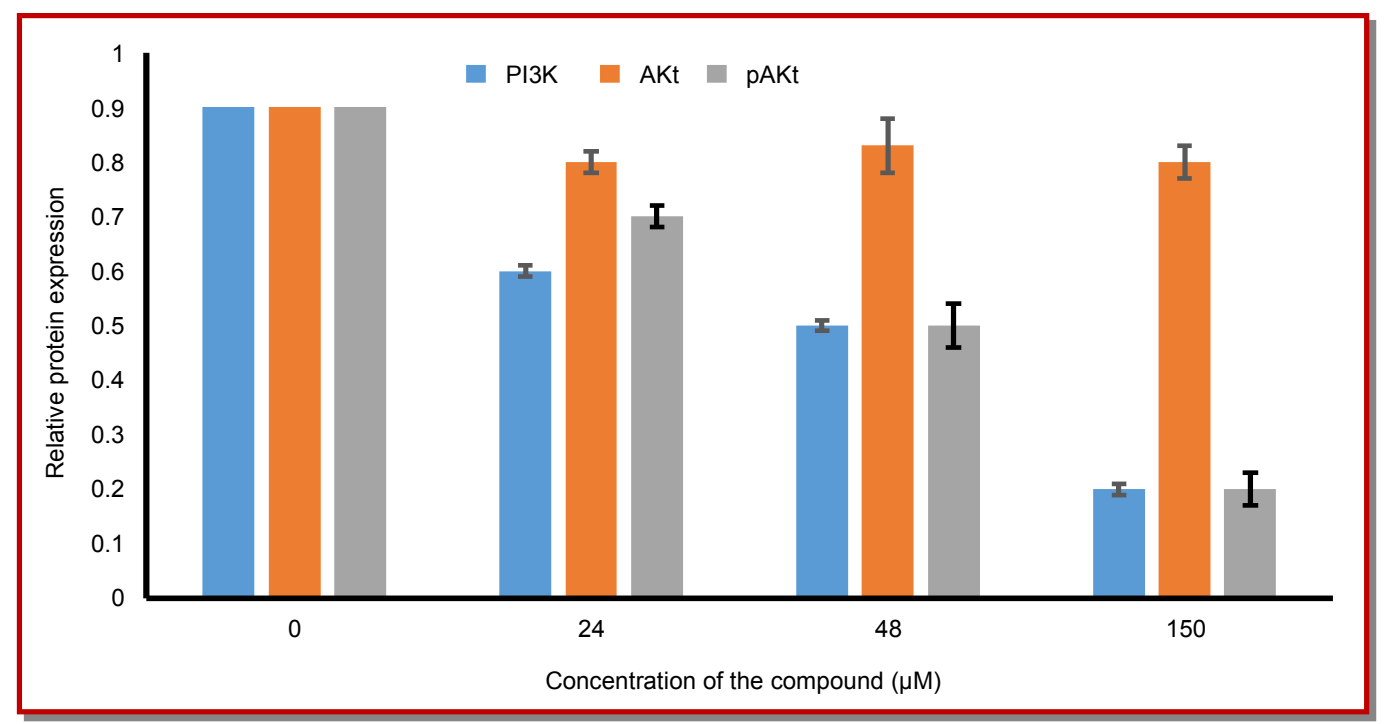

Figure 5: Effects of oxypeucedanin hydrate monoacetate on expression levels of pPI3K, Akt, pAkt. The Caco-2 cells were exposed to $0,24,48$ and $150 \mu \mathrm{M}$ dose of the compound for 48 hours and after which whole cell lysates were extracted and subjected to western blotting. The results represent the mean \pm S.D of at least three independent experiments 
trigger the process of apoptosis which finally lead to the activation of proteases (caspases) and nucleases, resulting in destruction of the cell (Adams and Cory, 2007; Cory and Adams, 2002). Oxypeucedanin hydrate monoacetate induced potent apoptosis in Caco-2 cancer cells as revealed by fluorescence microscopy. Literature survey revealed that oxypeucedanin hydrate has shown cytotoxic activity against epidermoid carcinoma cells (A -431 cells) (Kawaii et al., 2001).

\section{Conclusion}

The anti-cancer effects of oxypeucedanin hydrate mono -acetate isolated from $A$. dahurica are mediated via the induction of apoptosis, PI3K pathway and suppression of cancer cell migration in Caco-2 human colon carcinoma cells.

\section{Conflict of Interest}

The authors declare that there is no conflict of interest to reveal.

\section{Acknowledgements}

This study was supported by Graduate Student Research Innovation Project in Hunan Province (No. CX2014B356.) and the National Natural Science Foundation of China (No. 81173263).

\section{References}

Adams J, Cory S. The Bcl-2 apoptotic switch in cancer development and therapy. Oncogene 2007; 26: 1324-37.

Cory S, Adams J. The Bcl-2 family: Regulators of the cellular life-of-death switch. Nat Rev Cancer. 2002; 2: 647-56.

Fadeel B, Orrenius S, Zhivotovsky B. Apoptosis in human disease: A new skin for the old ceremony? Biochem Biophys Res Commun. 1999; 266: 699-717.

Hale AJ, Smith CA, Sutherland LC, Stoneman VE, Longthorne V, Culhane AC, Williams GT. Apoptosis: Molecular regula- tion of cell death. Eur J Biochem. 1996; 237: 884.

Jemal A, Bray F, Center MM, Ferlay J, Ward E, Forman D. Global cancer statistics. CA Cancer J Clin. 2011; 61: 69-90.

Kawaii S, Tomono Y, Ogawa K, Sugiura M, Yano M, Yoshizawa Y, Ito C, Furukawa H. Anti-proliferative effect of isopentenylated coumarins on several cancer cell lines. Anticancer Res. 2001; 21: 1905-11.

Kerr JF, Wyllie AH, Currie AR. Apoptosis: A basic biological phenomenon with wide-ranging implications in tissue kinetics. Br J Cancer. 1972; 26: 239-57.

Kinzler KW, Vogelstein B. Lessons from hereditary colorectal cancer. Cell. 1996; 87: 159-70.

Lee WJ, Chen WK, Wang CJ, Lin WL, Tseng TH. Apigenin inhibits HGF-promoted invasive growth and metastasis involving blocking PI3K/Akt pathway and beta 4 integrin function in MDA-MB-231 breast cancer cells. Toxicol Appl Pharmacol. 2008; 226: 178-91.

Liang CC, Park AY, Guan JL. In vitro scratch assay: A convenient and inexpensive method for analysis of cell migration in vitro. Nat Protoc. 2007; 2: 329-33.

Lin JC, Ho YS, Lee JJ, Liu CL, Yang TL, Wu CH. Induction of apoptosis and cell-cycle arrest in human colon cancer cells by meclizine. Food Chem Toxicol. 2007; 45: 935-44.

Neudauer CL, McCarthy JB. Insulin-like growth factor Istimulated melanoma cell migration requires phosphorinositide 3-kinase but not extracellular-regulated kinase activation. Exp Cell Res. 2003; 286: 128-37.

Reed JC, Tomaselli KJ. Drug discovery opportunities from apoptosis research. Curr Opin Biotechnol. 2000; 11: 586-92.

Samowitz WS, Curtin K, Ma KN, Edwards S, Schaffer D, Leppert MF, Slattery ML. Prognostic significance of p53 mutations in colon cancer at the population level. Int J Cancer. 2002; 99: 597-602.

Sebolt-Leopold JS, Dudley DT, Herrera R, Becelaere KV, Wiland A, Gowan RC, Tecle H, Barrett SD, Bridges A, Przybranowski S, Leopold WR, Saltiel AR. Blockade of the MAP kinase pathway suppresses growth of colon tumors in vivo. Nat Med. 1999; 5: 810-16.

Torrance CJ, Jackson PE, Montgomery E, Kinzler KW, Vogelstein V, Wissner A, Nunes M, Frost P, Discafani CM. Combinatorial chemoprevention of intestinal neoplasia. Nat Med. 2000; 6: 1024-28. 


\section{Your feedback about this paper}

1. Number of times you have read this paper 0

2. Quality of paper Click

3. Your comments

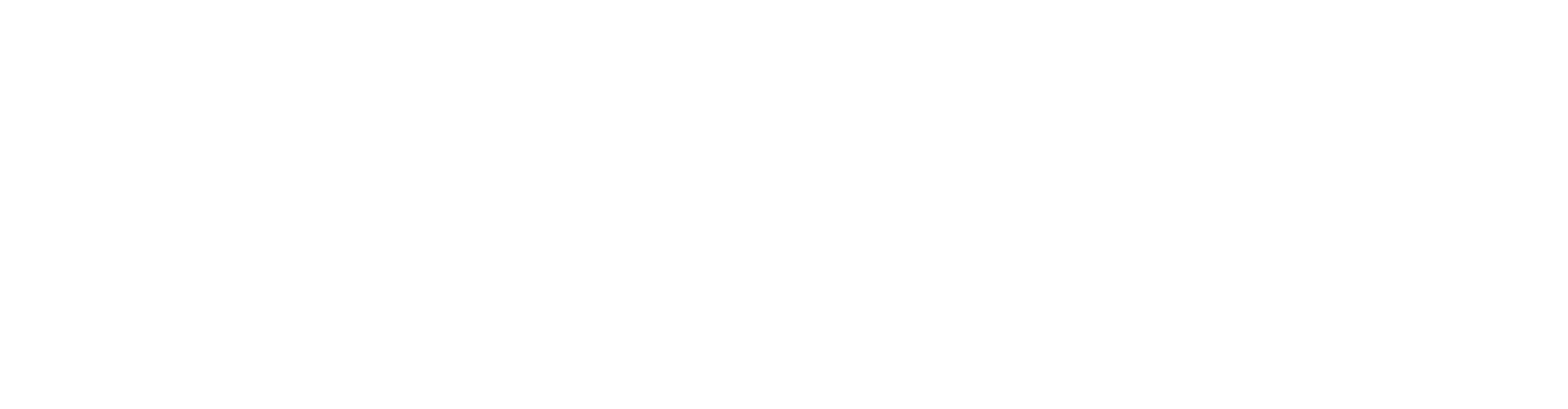

